\title{
Primary clear cell carcinoma of the larynx
}

\author{
G PESAVENTO,* A FERLITO, $\dagger$ AND G RECHER* \\ From the *ENT Division, Ospedale Civile, Vicenza, and the $\uparrow$ Section of Pathology, Department of \\ Otolaryngology, University of Padua, Padua, Italy
}

SUMMARY The clinical and pathological findings in three patients with clear cell carcinoma of the larynx are described. This type of neoplasm in the larynx is extremely rare. The aggressiveness of the tumour and its high biological malignancy are stressed.

Clear cell carcinoma (or large cell carcinoma, clear cell type) of the larynx has never been described, but one of us ${ }^{1}$ mentions this oncotype in a recent review of the histological types of laryngeal and hypopharyngeal cancers. This neoplasm is known to arise in the lung, though it is believed to be uncommon. Morgan and MacKenzie, ${ }^{2}$ who first described it accurately, state that it accounted for $2.6 \%$ of 380 lung cancers diagnosed at Westminster Hospital during the years 1947-62.

We report three cases of primary clear cell carcinoma of the larynx, diagnosed in the Section of Pathology of the Department of Otolaryngology, Padua University, during 1976-79.

\section{Case reports}

CASE 1

A 41-year-old man was admitted in November 1976, complaining of hoarseness of five months' duration. During a previous admission a diagnosis of poorly differentiated carcinoma of the larynx had been made. Clinical examination revealed enlarged lymph nodes in the left cervical region. A smaller lymph node could be palpated in the right lateral neck. Indirect laryngoscopy showed an ulcerated, fungating mass involving the laryngeal side of the epiglottis, the aryepiglottic fold, the false vocal cord, and the laryngeal ventricle of the left hemilarynx, which had no motility. A biopsy revealed clear cell carcinoma. He underwent total laryngectomy with tracheo-oesophageal shunt and bilateral neck dissection. The surgical specimen confirmed the diagnosis of clear cell carcinoma of the larynx with lymph node metastases. The postoperative course was

Received for publication 10 April 1980 normal. Monthly follow-up examinations until September 1977 revealed neither recurrence nor regional or distant metastases. As he no longer attended for follow-up, he was summoned to hospital but the family reported that he had died in June 1978 from the neoplastic disease.

CASE 2

A 61-year-old man complained of worsening dysphagia of six months' duration. One month before admission a biopsy of the larynx at another hospital had revealed a neoplasm.

On clinical examination he had bilaterally enlarged cervical lymph nodes. Indirect laryngoscopy showed an ulcerated, fungating lesion involving the epiglottis, the aryepiglottic fold, and the right false vocal cord. A biopsy revealed clear cell carcinoma. He underwent supraglottic laryngectomy with right lateral neck dissection and after the surgical specimen had confirmed the diagnosis of clear cell carcinoma of the larynx with lymph node metastases and invasion of the soft tissues of the neck a left lateral neck dissection was performed. This showed lymph node metastases. The postoperative course was normal. However, he was again admitted to hospital after two months because of a swelling around the tracheal stoma and dysphagia. A biopsy fragment removed from the right hypopharyngeal region showed recurrent tumour. His condition had rapidly deteriorated and further treatment was refused. He was discharged and died one month later. Necropsy was not permitted.

CASE 3

A 62-year-old man was admitted in December 1978. $\mathrm{He}$ complained of dysphagia for six months. One month before admission he had noticed swellings in 
the neck. Clinical examination revealed bilateral enlarged cervical lymph nodes. Indirect laryngoscopy showed an ulcerated growth involving the laryngeal side of the epiglottis and the aryepiglottic folds in their entirety. A biopsy was performed and revealed clear cell adenocarcinoma with papillary or secretory aspects. Total laryngectomy was performed together with bilateral radical neck dissection. Examination of the surgical specimens confirmed the diagnosis of clear cell carcinoma with bilateral lymph node metastases. The postoperative course was normal. As immunological monitoring showed a marked immune deficiency, non-specific immune restoration by means of BCG $(4 \mathrm{mg}$ in a four-week period by intradermal injection) was instituted. The patient was discharged in good general condition in February 1979. In April he presented at the ENT outpatient infirmary with swellings in the subhyoid and right lateral neck regions and laryngoscopy showed an ulcerated lesion involving the base of the

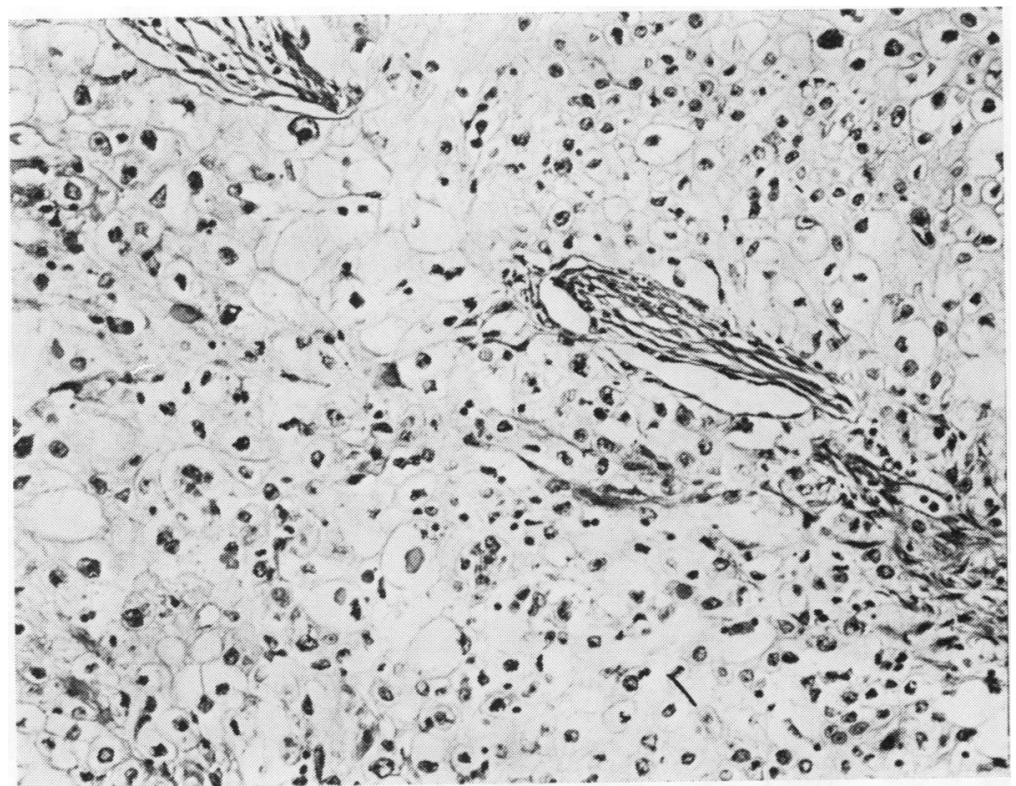

Fig. 1 The tumour is characterised by large cells displaying an 'empty' cytoplasm. Haematoxylin and eosin (original magnification $\times 40$ ).

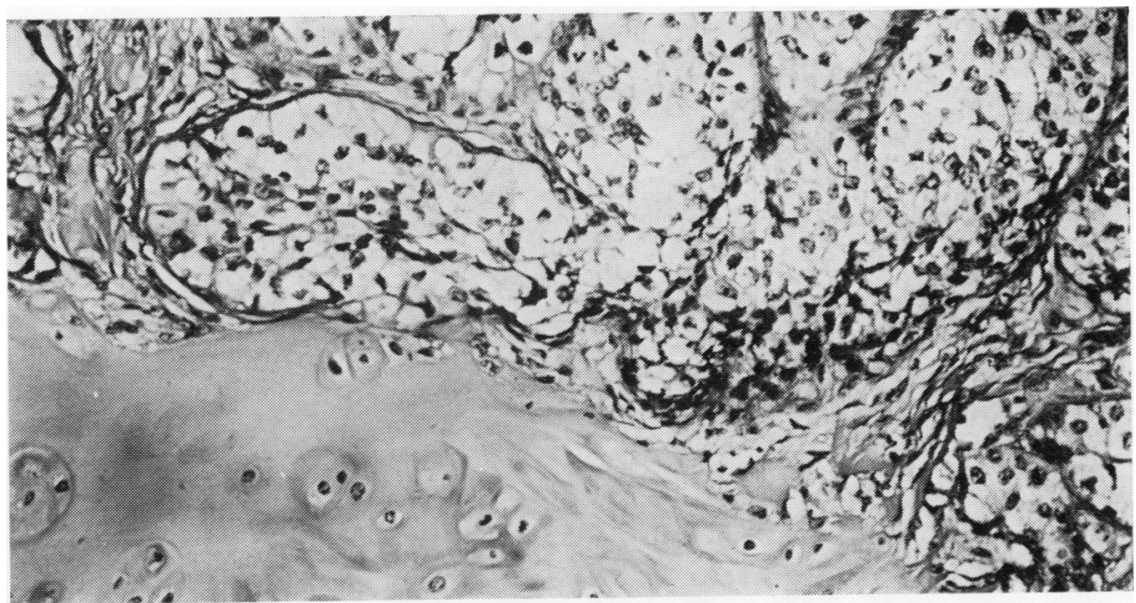

Fig. 2 The neoplasm appears to invade the cartilage. $H$ and $E$ (original magnification $\times 40)$. 
tongue. He was treated with radiation therapy (6000 rads) but no remission was induced, and the patient died in June 1979. Necropsy was not permitted.

\section{Pathology}

These three neoplasms exhibited no special macroscopic features. Microscopically, the neoplasms were composed of nests or clusters of large, round cells with clear, non-staining cytoplasm and small vesicular central nuclei. The cytoplasm was abundant and appeared to be 'empty' (Figs 1 and 2). Highly atypical, bizarre, multinucleated cells could also be seen. The tumours were composed basically of solid masses of clear cells bounded by fibrous tissue (Fig. 3). Areas of necrosis were also present.

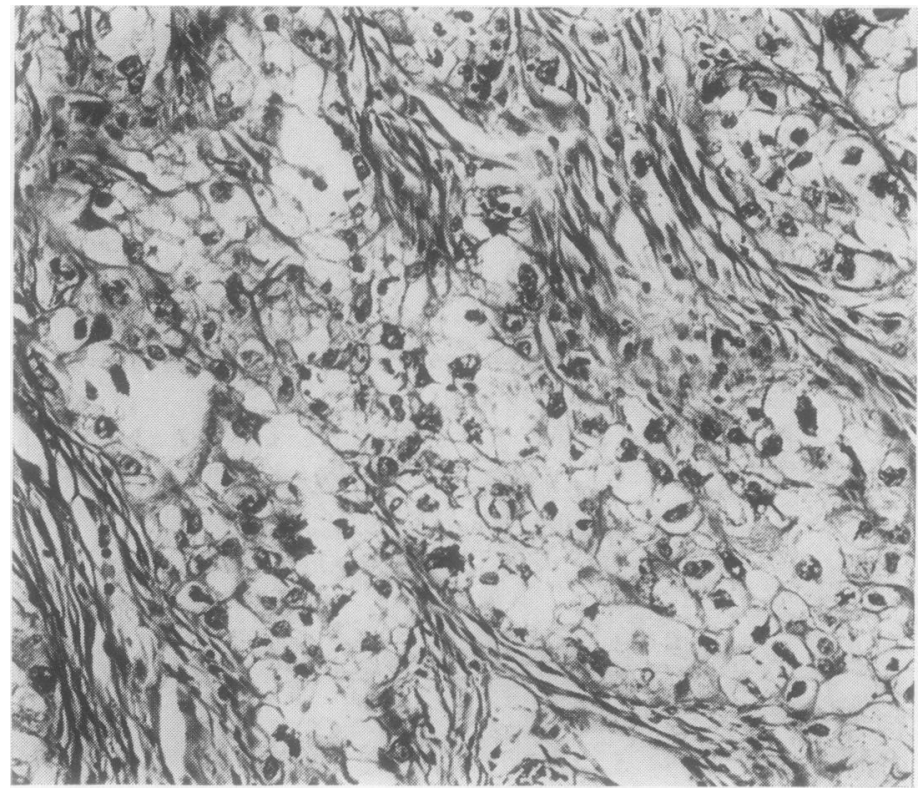

Fig. 3 The neoplasm, composed of clear large cells arranged in clumps, is intersected by fibrous tissue. $H$ and $E$ (original magnification $\times 40$ ).

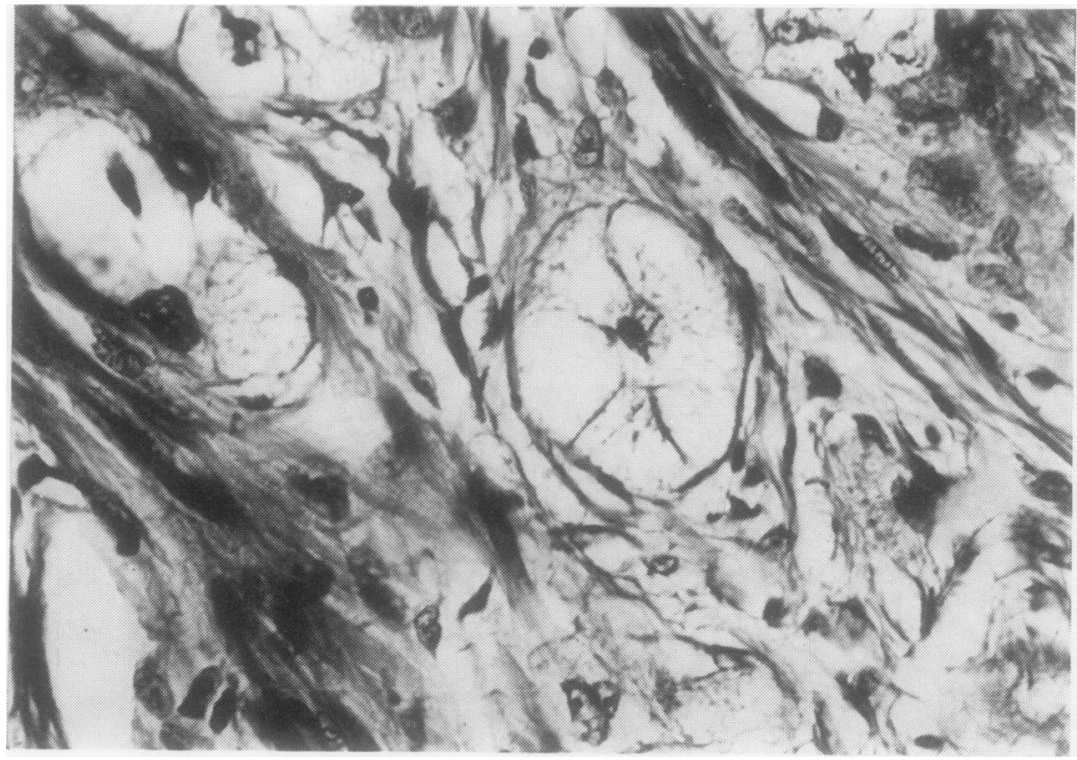

Fig. 4 Though the tumour has a solid appearance, its glandular origin can be seen. $H$ and $E$ (original magnification $\times 100$ ). 


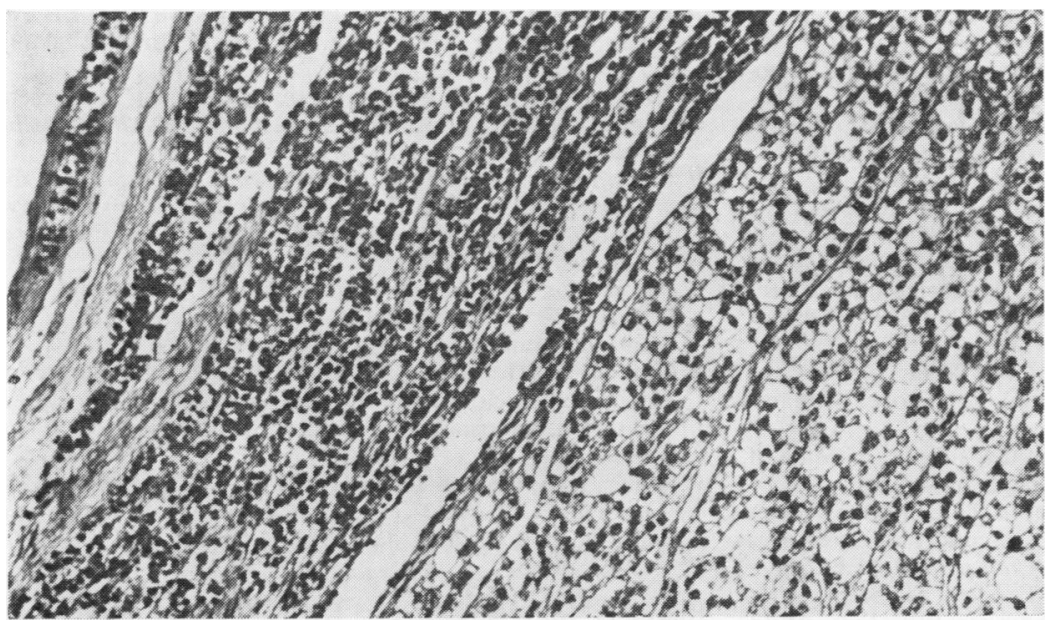

Fig. 5 Lymph node metastasis from clear cell carcinoma of the larynx. The histological pattern is the same as that of the primary neoplasm. $H$ and $E$ (original magnification $\times 16)$.

No squamous differentiation could be seen, but a thorough examination of many sections had revealed abortive glandular differentiation (Fig. 4). Histochemistry (PAS and DPAS) revealed no clear cells with intracellular mucin in their cytoplasm, whereas PAS-positive, diastase-resistant matter was present in the lumen of glandular-like and duct-like structures, and the clear cells were always PAS negative. The histological pattern of the lymph nodes containing metastases was the same as that of the primary neoplasms (Fig. 5).

\section{Discussion}

Clear cell carcinoma of the larynx has not been included in the classification recently proposed by Shanmugaratnam and Sobin. ${ }^{3}$

Ferlito $^{1}$ first mentioned briefly clear cell carcinoma of the larynx. Recently, Batsakis, ${ }^{4}$ in the new edition of Tumors of the Head and Neck, considered that clear cell carcinoma is extremely rare in the larynx.

Our three cases remove all doubts that this tumour occurs in the larynx. The neoplasm displays morphological characteristics similar to those of clear cell carcinoma of the lung ${ }^{2}$ and of major and minor salivary glands. As the latter are also present in the larynx, the occurrence of this tumour may be easily understood.

The lesion is basically a poorly differentiated adenocarcinoma, and this is apparent when the structural characteristics of the tumour are examined. Clear cell carcinoma and giant cell carcinoma ${ }^{5}$ of the larynx appear to be similar to the group of large cell carcinomas seen in the lung.

The differential diagnosis must be made from squamous cell carcinoma with hydropic cytoplasm and from metastases originating from clear cell carcinoma of the kidney. Neoplastic areas composed of clear cells may be found in several tumours, such as mucoepidermoid tumours and acinic cell carcinoma of salivary glands as well as glycogen-rich adenocarcinoma, adenosquamous carcinoma. There are also malignant mesenchymal neoplasms characterised by areas of clear cells, such as the clear cell chondrosarcoma 6 and the clear cell sarcoma of tendons and aponeuroses.? Malignant neoplasms displaying 'clear cells' and referred to as clear cell carcinomas have also been found in the thyroid gland, ${ }^{8}$ kidney, ${ }^{9}$ ovary, ${ }^{10}$ uterus, ${ }^{11}$ cervix, ${ }^{12}$ and vagina. ${ }^{13}$ It is obvious that the cell of origin is not always the same, as these neoplasms have different histogenetic, histochemical, and ultrastructural characteristics, though they show morphologically a common denominator, that is, the clear cell. In our three cases, the clear cells contained neither glycogen nor mucin. Clear cell tumours of the larynx and lung, as well as those involving major and minor salivary glands, may have a common histogenesis from ductal cells.

Though the biological behaviour of these rare tumours is not as yet well known because of the paucity of cases encountered, this malignant lesion seems to be associated with a poor prognosis, similar to that of clear cell carcinoma of the lung. All three patients described presented with diffuse cervical lymph node metastases and all died within a short period after diagnosis.

This work was supported by the Consiglio Nazionale delle Ricerche grant No. CT 77.01338.04. 


\section{References}

${ }^{1}$ Ferlito A. Histological classification of larynx and hypopharynx cancers and their clinical implications. Pathologic aspects of 2052 malignant neoplasms diagnosed at the ORL Department of Padua University from 1966 to 1976. Acta Otolaryngol (Suppl.) 1976;342:1-88

2 Morgan AD, MacKenzie DH. Clear-cell carcinoma of the lung. $J$ Pathol 1964;87:25-7.

${ }^{3}$ Shanmugaratnam K, Sobin LH. Histological Typing of Upper Respiratory Tract Tumours. International Histological Classification of Tumours No. 19. Geneva: World Health Organization, 1978.

${ }^{4}$ Batsakis JG. Tumors of the Head and Neck. Clinical and Pathological Consideration. 2nd ed. Baltimore: Williams and Wilkins Company, 1979.

${ }^{5}$ Ferlito A. Primary anaplastic giant cell adenocarcinoma of the larynx. J Laryngol Otol 1976;90:1053-60.

${ }^{6}$ Le Charpentier Y, Forest M, Postel M, Tomeno B, Abelanet R. Clear-cell chondrosarcoma. A report of five cases including ultrastructural study. Cancer $1979 ; 44: 622-9$.

${ }^{7}$ Tsuneyoshi M, Enjoji M, Kubo T. Clear cell sarcoma of tendons and aponeuroses. A comparative study of 13 cases with a provisional subgrouping into the melanotic and synovial types. Cancer $1978 ; 42: 243-52$.
- Variakojis D, Getz ML, Paloyan E, Strauss FH. II Papillary clear cell carcinoma of the thyroid gland. Hum Pathol 1975;6:384-90.

${ }^{9}$ Horn Y. Clear-cell carcinoma of the kidney: treatment with a precise technique using cobalt-60. Radiol Clin North Am 1975;44:470-4.

${ }^{10}$ Eastwood J. Mesonephroid (clear cell) carcinoma of the ovary and endometrium. A comparative prospective clinico-pathological study and review of the literature. Cancer 1978;41:1911-28.

11 Photopulos GJ, Carney CN, Edelman DA, Hughes RR, Fowler WC Jr, Walton LA. Clear cell carcinoma of the endometrium. Cancer 1979;43:1448-56.

12 Gompel C, Horanyl Z, Simonet ML. Ultrastructure of clear cell carcinoma of the vagina and cervix: report of a case with unusual ultrastructural findings. Acta Cytol $1976 ; 20: 262-5$.

${ }^{13}$ Noller KL, Decker DG, Symonds RE, Dockerty MB, Kurland LT. Clear-cell adenocarcinoma of the vagina and cervix: survival data. Am J Obstet Gynecol 1976; 124:285-8.

Requests for reprints to: Dr A Ferlito, Section of Pathology, Department of Otolaryngology, University of Padua, 35100 Padua, Italy, 